\title{
On the shear resistance of ferritic stainless steel composite slabs
}

\author{
Kathleen Lauwens*a,b, Maarten Fortan ${ }^{\mathrm{a}, \mathrm{b}}$, Itsaso Arrayago ${ }^{\mathrm{c}}$, Enrique Mirambell ${ }^{\mathrm{c}}$, Barbara Rossi ${ }^{\mathrm{a}}$ \\ ${ }^{a}$ KU Leuven, Department of Civil Engineering, Belgium \\ kathleen.lauwens@kuleuven.be, maarten.fortan@kuleuven.be, barbara.rossi@kuleuven.be \\ ${ }^{\mathrm{b}}$ Research Foundation Flanders, Belgium \\ ${ }^{c}$ Universitat Politècnica de Catalunya, Department of Civil and Environmental Engineering, Spain \\ itsaso.arrayago@upc.edu,enrique.mirambell@upc.edu \\ * Corresponding author at: KU Leuven, Department of Civil Engineering, Belgium.
}

\begin{abstract}
Steel-concrete composite floors are commonly used in construction due to their favourable weightto-depth ratio and erection time. Typically, concrete is poured onto a galvanised steel deck acting as formwork. However in case of floors exposed to corrosive environments, stainless steel is likely to be chosen over galvanised steel. Besides its better corrosion resistance, stainless steel also offers desirable aesthetic appearance and good mechanical properties. Composite slabs can fail in bending, vertical shear or longitudinal shear. The latter failure mode is the most common, and its prediction depends on values obtained through full-scale tests. However, for stainless steel decks, no specific treatment exists in current design standards. This paper investigates the longitudinal shear resistance of stainless steel composite slabs through an experimental study. One short and three long span slabs, made using a Cofraplus 60 ferritic EN1.4003 stainless steel corrugated deck, are tested in accordance with Eurocode 4, annex B.3 [1]. The Partial Shear Connection (PSC) method is used to assess the longitudinal shear resistance. The experimental results, together with the results provided in Task 3.3 of the "Structural Applications of Ferritic Stainless Steels (SAFSS, RFSR-CT-2010-00026)" project [2], are used to draw conclusions on the applicability of ferritic stainless steel decks in composite floors.
\end{abstract}

Keywords: ferritic stainless steel, composite floors, longitudinal shear resistance 


\section{INTRODUCTION}

Steel-concrete composite slabs are commonly used because they combine the favourable mechanical properties of a profiled steel deck, acting as tensile reinforcement, and a concrete slab in compression. Moreover, the deck is also a permanent formwork. An additional light tensile reinforcement is still needed to control cracking due to shrinkage and temperature effects and to ensure fire safety. Where necessary, at the level of the intermediate supports or when the sheeting itself does not provide enough tension resistance for instance, additional reinforcement is foreseen in the upper or lower part of the slab respectively. The amount of concrete in the tensile area of the slab is significantly reduced, as a result of the re-entrant shape of the steel deck, leading to a lower self-weight of the whole construction. Furthermore, the steel decks are light and therefore easily and fastly mounted, providing a safe working platform.

Composite slabs can fail in bending, vertical shear or longitudinal shear. Since the latter is the most common failure mode [3], the shear connection is of great importance to transmit the longitudinal shear forces and to limit the slip between concrete and steel. This connection is based on a chemical, frictional and mechanical bond [4]. The chemical (adhesive) bond is a consequence of the curing of the cement and breaks via a brittle mode when first slip occurs. Once that bond is broken, friction between the concrete and the steel occurs. The frictional force is directly proportional to the force perpendicular to the contact surface. However, the most important contribution to the shear resistance is the mechanical bond, a physical interlocking occurring subsequently to bending via a clamping action of the deck with its embossment or indentations. The shear connection is a complex phenomenon, influenced by many parameters, e.g. the type, size, spacing, but mainly the depth of the embossments [5], the shape and thickness of the steel sheet, the slenderness of the slab, the type of end anchorage and the shear span length [6].

Stainless steel is an alloy with at least $10.5 \%$ of chromium and maximum $1.2 \%$ of carbon content in mass [7]. Chromium, together with other alloying elements, leads to the development of a thin, 
passive film when exposed to oxygen, which provides corrosion resistance and which self-repairs when damaged. This means that stainless steel slabs, in comparison to traditional carbon steel slabs, do not need any kind of coating or maintenance. Ferritic stainless steels contain little or no nickel, and hence are cheaper and more price-stable than the other stainless steel families. Furthermore their corrosion resistance is lower, though still significantly superior to that of carbon steel. Besides stainless steel decks have good fire resistance. According to [2], ferritic stainless steel decks retain more of their initial strength than galvanised steel when subjected to high temperature. Corrosion resistance combined with fire resistance makes ferritic stainless steel an economic alternative for composite decks in many applications, such as car parks.

It is worth noting that the deflections of elastic beams, which can be estimated by standard structural theory, should, for stainless steel structures, be evaluated based on the secant modulus of elasticity instead of the standard modulus of elasticity. Values of the secant moduli should be evaluated for the appropriate serviceability design stress $\sigma_{\mathrm{i}, \mathrm{Ed}, \mathrm{ser}}$. For ferritic stainless steel, the parameter $\mathrm{n}$, which is a measure of the non-linearity of the stress-strain curve, is the highest of all the stainless steel families. Therefore, the additional deflections at the serviceability limit state, compared to the same member made of carbon steel with a Young's modulus of $200000 \mathrm{MPa}$, are neglectable. For $\sigma_{\mathrm{i}, \mathrm{Ed} \text {,ser }}$ equal to $80 \%$ of the yield strength, the extra deflections for a simply supported slab will be less than $10 \%$.

Since no pure analytical models of the longitudinal shear resistance have yet been developed, both calculation methods for the design resistance available in Eurocode 4 [1], the m-k method and the Partial Shear Connection (PSC) method, rely on full-scale tests.

The m-k method uses two empirical parameters, $\mathrm{m}$ and $\mathrm{k}$, to calculate the resistance to longitudinal shear which should be obtained from two test series of three slabs. The m-k method is applicable to both ductile and brittle connections and provides good results when different span lengths $\mathrm{L}_{\mathrm{s}}$ or slab thicknesses $h_{t}$ are used. Nonetheless two significant disadvantages might be pointed out. Firstly, the 
values $\mathrm{m}$ and $\mathrm{k}$ lack physical significance and are not directly related to the shear bond. Secondly, since two test series of at least three specimens are necessary, the cost of the experimental programme for their determination increases.

The Partial Shear Connection (PSC) method is an alternative to the m-k method but can only be used for ductile longitudinal shear connections. This approach is based on the determination of the longitudinal shear strength from the ultimate bending moment. In contrast to the parameters $\mathrm{m}$ and $\mathrm{k}$, the obtained longitudinal shear strength $\tau_{\mathrm{u}, \mathrm{Rd}}$ has a physical meaning, i.e. the degree of interaction between the corrugated sheet and the concrete. Furthermore it offers the advantage that less tests need to be conducted to obtain valuable results for a particular deck. EN 1994-1-1 annex B.3.2 §7 [1] mentions that a series of four tests showing ductile longitudinal shear failure modes should be conducted: a group of three slabs with a length as long as possible and one slab having the shortest length possible, but not less than $3 h_{t}$. It should be noted that the accuracy is slightly lower than for the m-k method and the derived coefficient is only valid for that particular type of deck [3].

Since both the m-k and the PSC method require full-scale testing which is expensive and time consuming, "small-scale" tests, known as the push-out or pull-out tests, have been developed. The literature provides a variety of setups which are divided into two categories: tests with and without external lateral constraining forces. Small-scale tests cannot replace full-scale tests since several important factors are not taken into account. For example, the influence of the curvature due to bending is neglected and there is no inclusion of the ratio between the effective depth and the shear span [8], although the latter may be addressed using finite element models in combination with smallscale tests.

In the present paper, the PSC method is used to address the longitudinal shear resistance of stainless steel composite slabs. The method was preferred seen its straightforwardness and since it provides insight into the actual connection behaviour between the corrugated sheet and the concrete. 
This research deals with stainless steel composite slabs made of EN1.4003 ferritic stainless steel, fabricated via the same production line than for galvanized steel [11]. The article starts with a description of a series of full scale tests performed on composites slabs according to EN 1994-1-1 annex B.3 [1]. After a theoretical investigation of the partial interaction curve according to the PSC method, the longitudinal shear resistance is discussed and the behaviour of the stainless steel slabs is compared to galvanized steel Cofraplus 60 composite slabs.

\section{EXPERIMENTAL PROGRAMME}

All the tests in the present paper, conducted in accordance with EN 1994-1-1:2004 annex B.3 [1], were carried out in the frame of a master thesis [9]. The results will be combined with the six tests described within Task 3.3 of the Research Fund of Coal and Steel (RFCS) project "Structural Applications of Ferritic Stainless Steels (SAFSS, RFSR-CT-2010-00026)" [2] in order to draw conclusions on the applicability of ferritic decks in composite floors. The notations presently used in this chapter are in accordance with EN 1994-1-1:2004 [1].

\subsection{Specimens}

The experimental programme consists of four tests: three long (S1, S2 and S3) and one short (S4) composite slabs with ferritic stainless steel sheeting. An overview of the characteristics of the four slabs can be found in Table 1.

The stainless steel sheeting is a $0.80 \mathrm{~mm}$ thick Cofraplus 60 profiled deck made of the EN1.4003 ferritic grade. The stainless steel slabs are fabricated using the same production line than for galvanized steel [11]. One could question the ability of ferritic corrugated sheets to transmit the longitudinal shear force since these grades present a more rounded stress-strain curve than traditional carbon steel, without a yield plateau, leading to dissimilar deformability when the same cold forming tools are used. However, the measured spacing and depth of the embossments of the stainless steel specimens did not deviate from the nominal values by more than $5 \%$ and $10 \%$ respectively and the mean measured depth of the embossments of the stainless steel sheet is $2.775 \mathrm{~mm}$, as given in [2]. 
The cross-sectional geometry and the cross-sectional characteristics of this sheet can be found in Fig. 1 and Table 2 respectively. The tensile yield strength $\mathrm{f}_{\mathrm{yp}}$ measured from tensile tests reported in [2] equals $326 \mathrm{~N} / \mathrm{mm}^{2}$.

Table 1. Slab characteristics

\begin{tabular}{lccllll}
\hline Slab & Total length & Span length $\mathrm{L}$ & Shear span length $\mathrm{L}_{\mathrm{s}}$ & Height $\mathrm{h}_{\mathrm{t}}$ & Width $\mathrm{b}$ & Self-Weight \\
\hline $\mathrm{S} 1$ & $2000 \mathrm{~mm}$ & $1800 \mathrm{~mm}$ & $450 \mathrm{~mm}$ & $100 \mathrm{~mm}$ & $1080 \mathrm{~mm}$ & $3.43 \mathrm{kN}$ \\
$\mathrm{S} 2$ & $2000 \mathrm{~mm}$ & $1800 \mathrm{~mm}$ & $450 \mathrm{~mm}$ & $100 \mathrm{~mm}$ & $1080 \mathrm{~mm}$ & $3.43 \mathrm{kN}$ \\
$\mathrm{S} 3$ & $2000 \mathrm{~mm}$ & $1800 \mathrm{~mm}$ & $450 \mathrm{~mm}$ & $100 \mathrm{~mm}$ & $1080 \mathrm{~mm}$ & $3.43 \mathrm{kN}$ \\
$\mathrm{S} 4$ & $1500 \mathrm{~mm}$ & $1300 \mathrm{~mm}$ & $325 \mathrm{~mm}$ & $100 \mathrm{~mm}$ & $1080 \mathrm{~mm}$ & $2.57 \mathrm{kN}$ \\
\hline
\end{tabular}
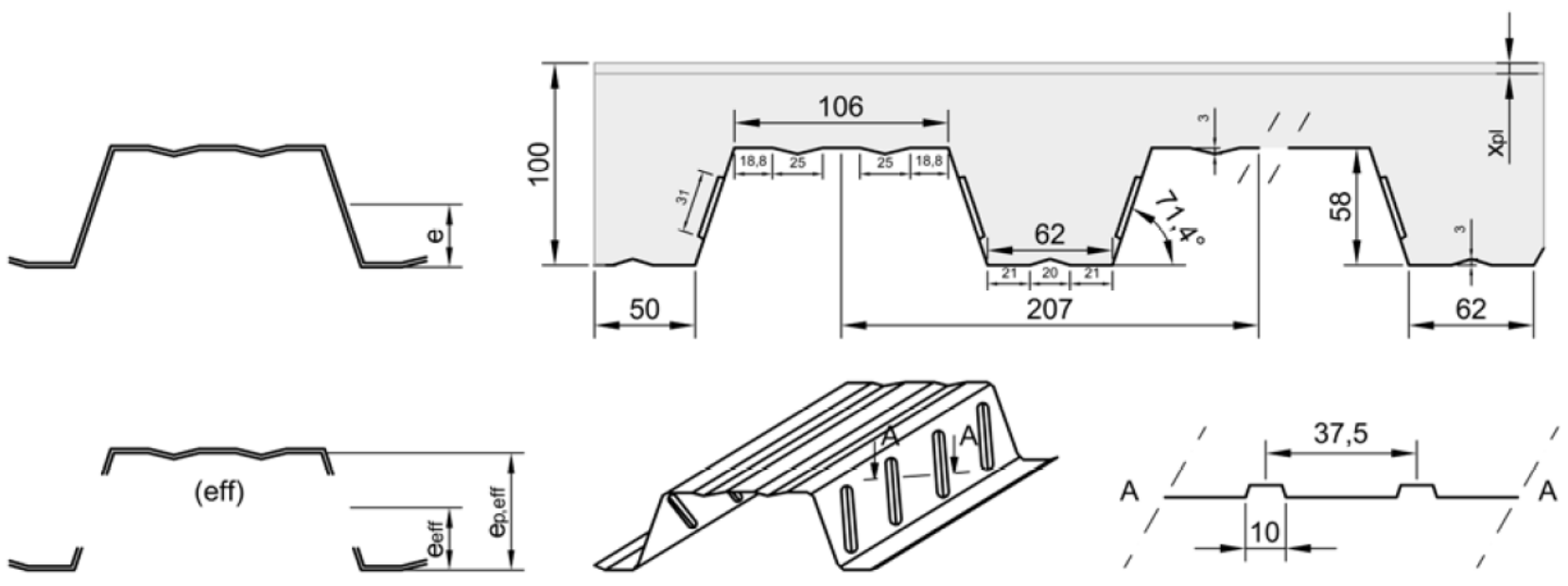

Fig. 1. Cross-section geometry of the Cofraplus 60 deck [2, 10]

Table 2. Characteristics of the Cofraplus 60 deck [2]

Overall depth

$\mathrm{h}_{\mathrm{p}}$

$58.0 \mathrm{~mm}$

Distance from the centroidal axis of the effective steel deck to the extreme fibre $e_{\text {eff }}$

of the composite slab in tension.

$33.3 \mathrm{~mm}$

Distance from the plastic neutral axis of the effective steel deck to the extreme $e_{p, \text { eff }}$

$57.6 \mathrm{~mm}$

fibre of the composite slab in tension.

Cross-sectional area

$\mathrm{A}_{\mathrm{p}}$

$1211 \mathrm{~mm}^{2}$

Effective cross-sectional area

$\mathrm{A}_{\mathrm{pe}}$

$910 \mathrm{~mm}^{2}$ 
All composite slabs were fabricated with identical concrete compositions. The composition of the used concrete mix is presented in Table 3. The drying process for sand and gravel was conducted according to NBN EN 1097-5 [12] for each supply of concrete and the workability of the concrete was improved using superplasticiser until a consistency of S3 was reached.

Table 3. Concrete composition

\begin{tabular}{lll}
\hline & Type & Quantities \\
\hline Cement & CEM I 52.5N & $306 \mathrm{~kg} / \mathrm{m}^{3}$ \\
Gravel (dry) & $4 / 16$ & $1253 \mathrm{~kg} / \mathrm{m}^{3}$ \\
Sand (dry) & $0 / 4$ & $631 \mathrm{~kg} / \mathrm{m}^{3}$ \\
Water & & $171 \mathrm{~kg} / \mathrm{m}^{3}$ \\
Superplasticiser & MasterGlenium 51 & $1.159 \mathrm{~kg} / \mathrm{m}^{3}$ \\
\hline
\end{tabular}

Concrete cubes with dimensions $150 \times 150 \times 150 \mathrm{~mm}$ were made to determine the concrete strength according to NBN EN 12390 [13]. A total of six cubes were obtained for each slab, three of which were cured at the identical location as their associated slab and tested on the same day of the fourpoint bending test. The remaining cubes were cured at $90 \%$ air humidity and a constant temperature of $20^{\circ} \mathrm{C}$ and tested after 28 days to determine the concrete strength. Prior to testing, all the dimensions were measured with an accuracy of $0.1 \mathrm{~mm}$. After 28 days, the concrete strength class C45/55 was obtained. On the test date, the average cylindrical compressive strength of the concrete was equal to $52.5 \mathrm{~N} / \mathrm{mm}^{2}$ with a standard deviation of $1.9 \mathrm{~N} / \mathrm{mm}^{2}$.

Crack inducers (see Fig. 2), with the same cross-sectional geometry as the sheeting, were placed directly under the applied line loads to eliminate the tensile resistance of the concrete. As prescribed 
by EN 1994-1-1:2004 [1], the height of the crack inducers does not need to cover the whole free height of the slab. Measured on the top ribs, the height was $15 \mathrm{~mm}$, allowing the crack inducers to be used as spacers for the reinforcement. The $0.80 \mathrm{~mm}$ thick aluminium crack inducers were coated with debonding agent before pouring the concrete. All the specimens were fully supported during casting. No efforts to improve the connection between the concrete and the steel sheeting were made. All the composite slabs had identical reinforcement i.e. a "QS130A" reinforcement mesh, which consists of $5 \mathrm{~mm}$ diameter rebars with a spacing of $150 \mathrm{~mm}$. The formwork and its components are displayed in Fig. 2.

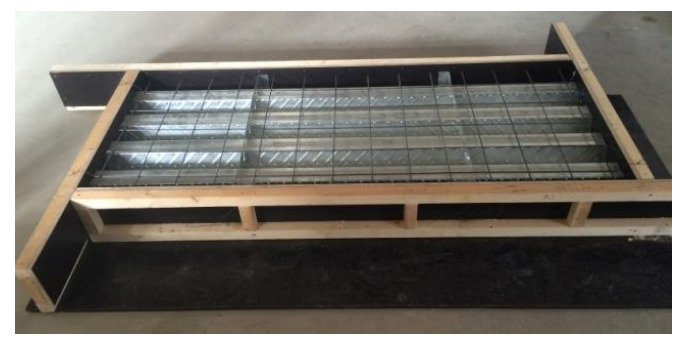

Fig. 2. Formwork, crack inducers and reinforcement

\subsection{Description of the test setup}

Four-point bending tests, which were arranged in accordance with EN 1994-1-1 annex B.3 [1] (see Fig. 3), were conducted on simply supported slabs. The slabs were subjected to two identical line loads, located at L/4 and 3L/4, which covered the complete width of the slab. A uniform distribution of forces was obtained by providing neoprene pads between the slab and the rebar $(10 \mathrm{~mm})$ attached to the spreader beams. The overhang at both sides of the slab was taken as $100 \mathrm{~mm}$, which is exactly the maximum value allowed in [1]. The width of the bearing plates were also limited to $100 \mathrm{~mm}$. The shear span length $\mathrm{L}_{\mathrm{s}}$ was $450 \mathrm{~mm}$ for the long slabs S1-S3 and $325 \mathrm{~mm}$ for the short slab S4. 


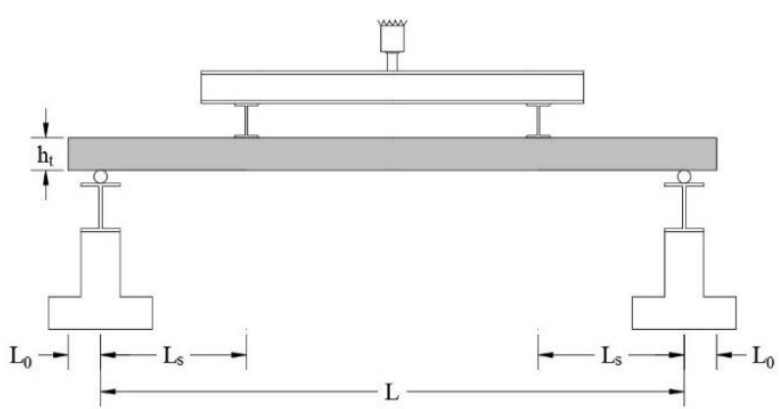

(a)

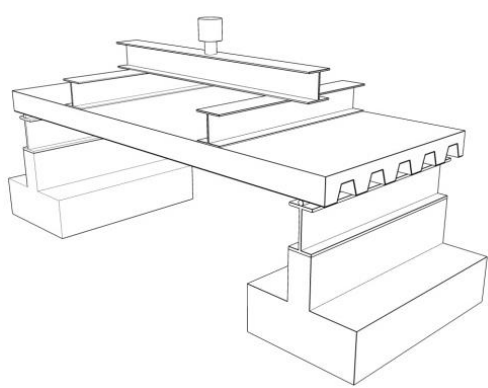

(b)

Fig. 3. a) 2D drawing of the test setup; b) 3D drawing of the test setup

A spreader system with a total weight of $1.59 \mathrm{kN}$ distributed the load onto the two lines. The displacements were measured by displacement transducers (LVDT) at five locations A, B, C, D and E as shown in Fig. 4. LVDT A was located above the composite slab next to the spreader beam measuring the midspan deflection, while LVDTs B and C measured the vertical displacement of the supports. LVDTs D and E were mounted onto a treaded rod attached to the concrete section of the slab through expansion anchors to measure the relative slip between the steel sheeting and the concrete.

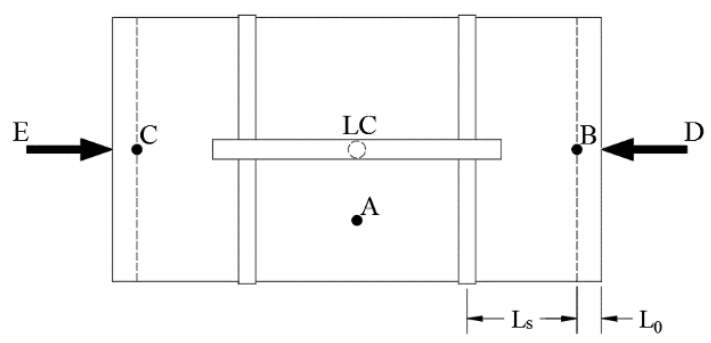

(a)

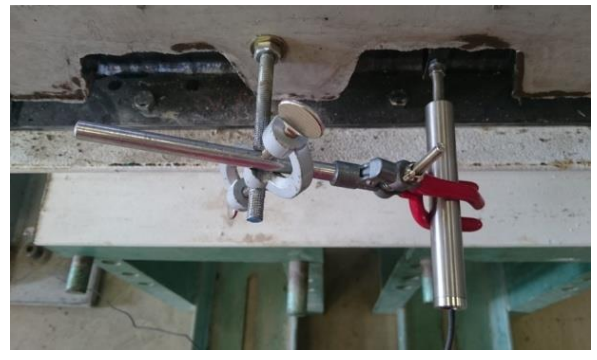

(b)

Fig. 4. a) Testing setup with location of LVDTs; b) Photograph of LVDT D connected to the concrete by a treated rod

\subsection{Loading protocol}

The loading procedure as described in EN 1994-1-1 [1] requires a cyclic loading followed by a static one until failure is reached. The preceding cyclic loading's effect is to remove any chemical bond between the steel deck and the concrete. Research has been conducted questioning the effect of the chemical bond as well as the importance of the cyclic loading on the behaviour of the composite slab. One could intuitively conclude that the behaviour of the slab after the removal of the chemical bond 
would be less stiff. But, in [14], Cifuentes and Medina stated that the chemical bond can safely be neglected since no noticeable difference is found in the maximum load carrying capacity, although a higher midspan deflection and end slip at ultimate loading is reached for specimens without prior cyclic loading. Wright et al. [15] and Hedaoo et al. [6] also pointed out the uselessness of the required cyclic loading on the determination of the ultimate load.

The influence of the cyclic loading was investigated in the present study, by carrying out a reduced amount of cycles on slab S2 and S3, 10 and 20 cycles respectively, while no cyclic loading was applied on slab S1 and S4. The values of the required load interval for the cyclic loading were obtained using the failure load $F_{\max }$ of slab S1. The lower boundary of the load interval should not exceed $0.2 \mathrm{~F}_{\max }$ while the upper boundary cannot be less than $0.6 \mathrm{~F}_{\max }$. Including the self-weight of the load distribution components, the lower and upper boundaries were $10.7 \mathrm{kN}$ and $32.1 \mathrm{kN}$, respectively. Cyclic loading was achieved at an average rate of two minutes per cycle, while for static tests the average loading rate is $0.66 \mathrm{kN} / \mathrm{min}$.

It will be shown in the next paragraphs (see Fig. 5 to Fig. 8 and

Table 4) that the chemical bond was indeed broken after the second load cycle. The results confirm that the cyclic loading had no influence on the maximum bending moment, but that the deflection at this maximum load was bigger when no initial cyclic test had been performed on the specimen. The influence of the cyclic test on the slip at maximum load as found in [14] is, possibly due to the low amount of cycles, not noticeable because of the scatter in the results. Furthermore the results show a stabilization of the midspan deflection and the end slip with an increasing amount of cycles.

\subsection{Results}

Typical behaviour of composite slabs, as described by Daniels in [16], can be observed from the obtained results, shown in Fig. 5 to Fig. 8 for slabs S1 to S4, respectively. The initial phase reflects an uncracked specimen with elastic material behaviour and with a full interaction between concrete and steel. With increased loading, small cracks start to appear uniformly distributed over the span of 
the slab, slowly gaining significance in the load application zones. The first point of significance (X) is characterised by the introduction of the first slip, not necessarily simultaneously at both sides of the composite slab. At this point, the load drops and the rigidity of the composite slab decreases due to the loss of interaction between the steel and concrete, as shown Fig. $9(a)$ and $(b)$. Subsequently to the increase of the imposed load, cracks in the load application zone grow, while cracks in other zones remain stable. When slipping appears at both sides of the slab, a drop in the force (point of significance Y) can be noticed followed by the attainment of the maximum force (point of significance Z). Cracks reach the surface of the slab in the loading zone, Fig. 9 (c), while in the profile sheeting plastic deformation, Fig. $9(d)$, occurs.
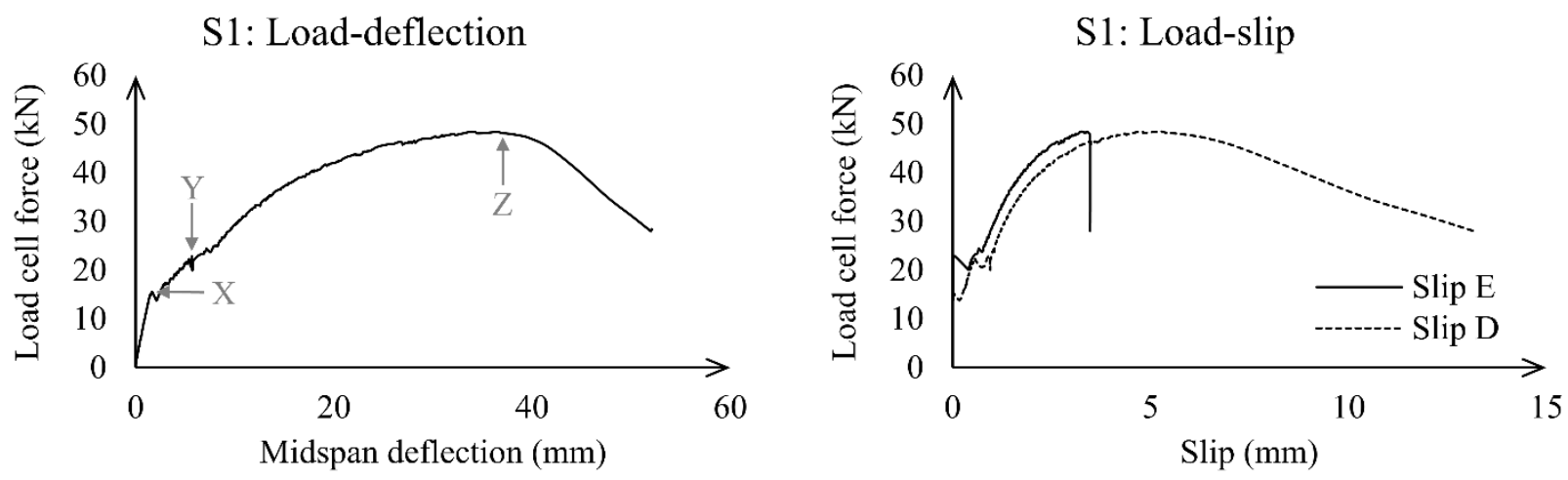

Fig. 5. Load-deflection and load-slip curves for slab S1
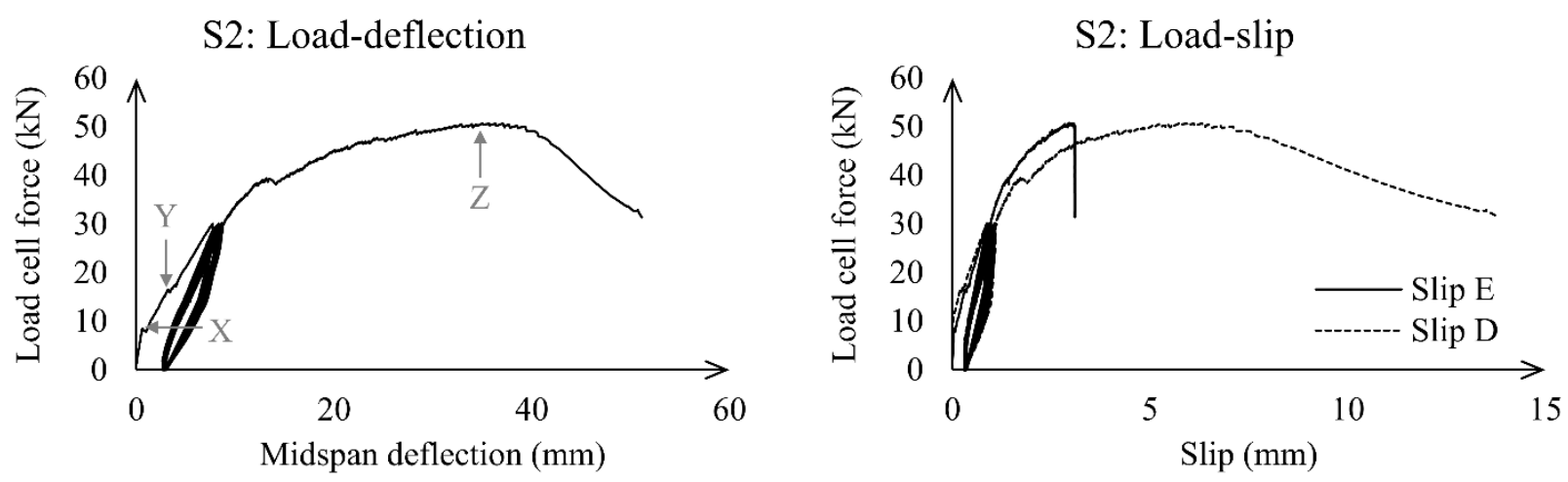

Fig. 6. Load-deflection and load-slip curves for slab S2 
S3: Load-deflection

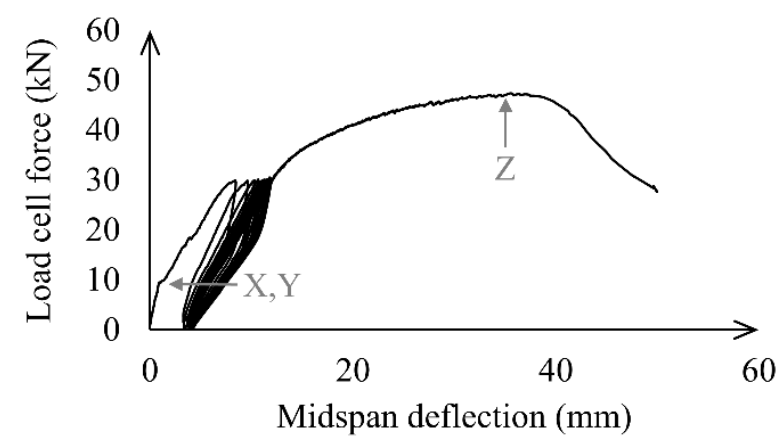

S3: Load-slip

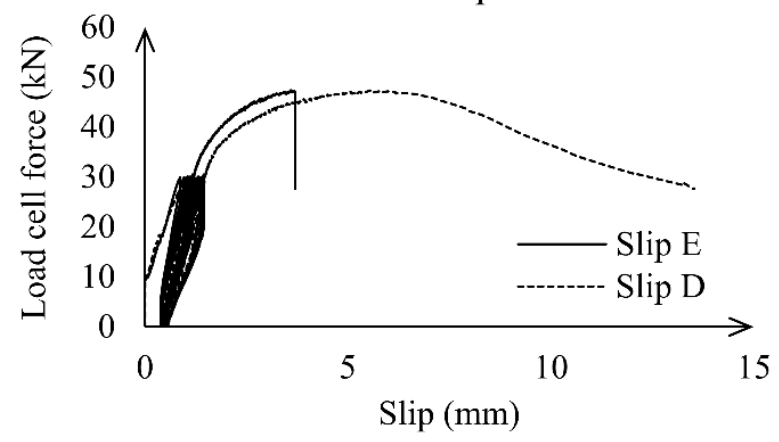

Fig. 7. Load-deflection and load-slip curves for slab S3
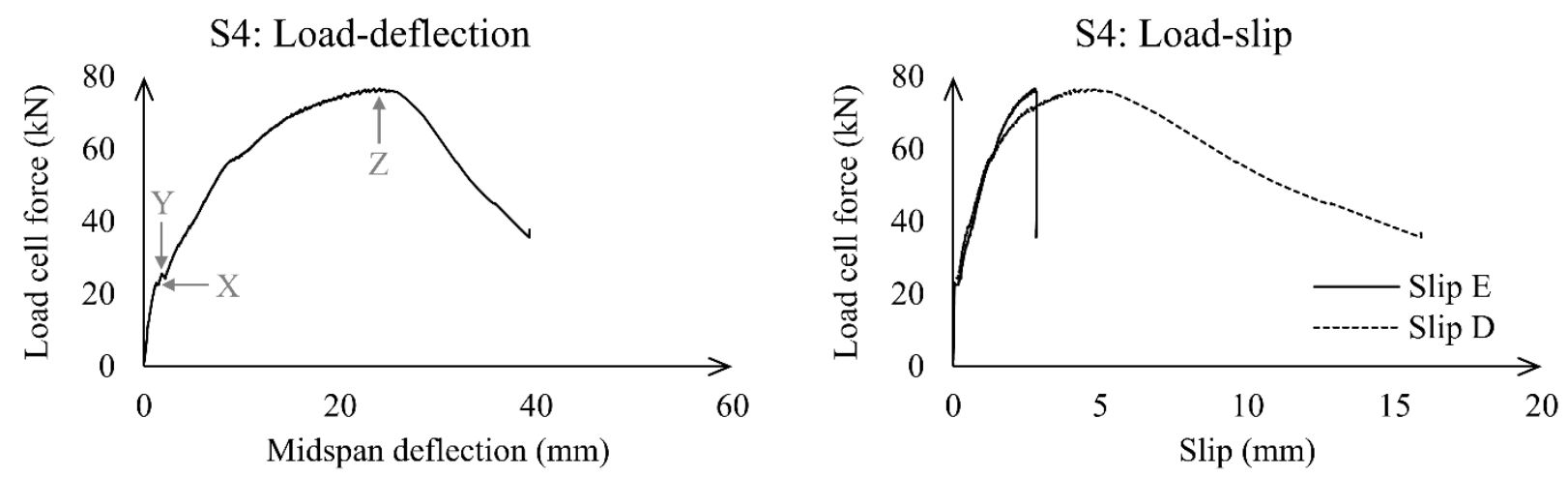

Fig. 8. Load-deflection and load-slip curves for slab S4

All composite slabs showed ductile behaviour according to the definition provided in NBN EN 19941-1:2004 annex B.3 [1]. Eurocode 4 considers failure of the shear connection as ductile if the failure

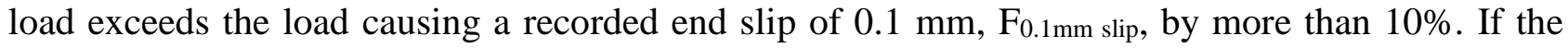
deflection at midspan exceeds the length $\mathrm{L}$ over 50, as recommended in EN 1994-1-1 article 9.7.3 (3) [1], the corresponding load should be taken as the failure load. All failure modes of the slabs are categorized as longitudinal shear.

Table 4 gives key results for all slabs including the midspan deflections $\delta_{\mathrm{Fmax}}$ and the end slips $\mathrm{D}_{\mathrm{Fmax}}$ and $\mathrm{E}_{\mathrm{Fmax}}$ at the maximum load $\mathrm{F}_{\max }$. The reported values include the readings from the load cell (Fig. 5 - Fig. 8$)$, the weight of the spreader system $(1.59 \mathrm{kN})$ and the self-weight of the slabs (Table 1$)$.

Table 4. Key results of the composite slab tests

\begin{tabular}{lllllll}
\hline Slab & $\mathrm{F}_{0.1 \mathrm{~mm} \text { slip }}$ & $1.1 \mathrm{~F}_{0.1 \mathrm{~mm} \text { slip }}$ & $\mathrm{F}_{\max }$ & $\delta_{\text {Fmax }}$ & Slip D Fmax & Slip $\mathrm{E}_{\text {Fmax }}$ \\
\hline $\mathrm{S} 1$ & $19.54 \mathrm{kN}$ & $21.49 \mathrm{kN}$ & $53.46 \mathrm{kN}$ & $36.48 \mathrm{~mm}$ & $5.26 \mathrm{~mm}$ & $3.41 \mathrm{~mm}$
\end{tabular}




\begin{tabular}{llllllc}
\hline Slab & $\mathrm{F}_{0.1 \mathrm{~mm} \mathrm{slip}}$ & $1.1 \mathrm{~F}_{0.1 \mathrm{~mm} \text { slip }}$ & $\mathrm{F}_{\max }$ & $\delta_{\text {Fmax }}$ & Slip D Fmax & Slip E \\
\hline S2 & $14.19 \mathrm{kN}$ & $15.61 \mathrm{kN}$ & $55.78 \mathrm{kN}$ & $35.03 \mathrm{~mm}$ & $5.75 \mathrm{~mm}$ & $2.95 \mathrm{~mm}$ \\
$\mathrm{~S} 3$ & $15.50 \mathrm{kN}$ & $17.05 \mathrm{kN}$ & $52.37 \mathrm{kN}$ & $35.52 \mathrm{~mm}$ & $5.57 \mathrm{~mm}$ & $3.59 \mathrm{~mm}$ \\
$\mathrm{~S} 4$ & $26.60 \mathrm{kN}$ & $29.26 \mathrm{kN}$ & $80.77 \mathrm{kN}$ & $24.03 \mathrm{~mm}$ & $4.62 \mathrm{~mm}$ & $2.78 \mathrm{~mm}$ \\
\hline
\end{tabular}

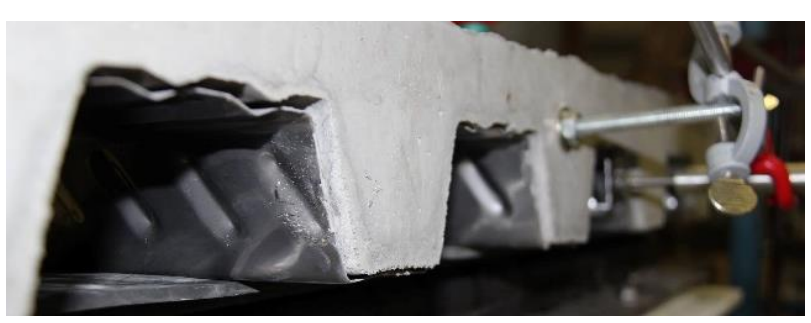

(a)

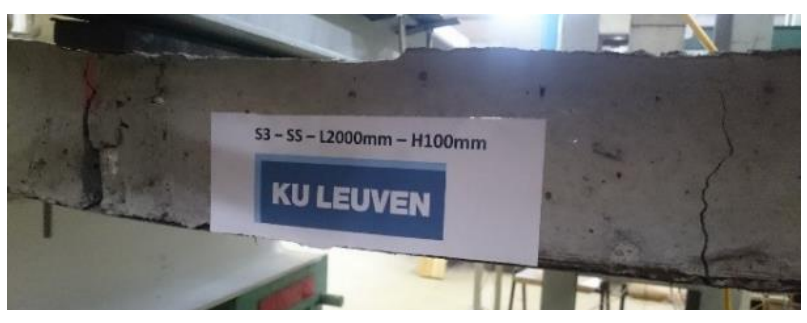

(c)

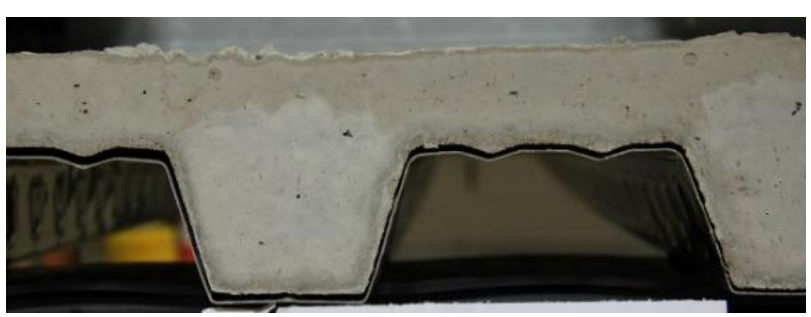

(b)

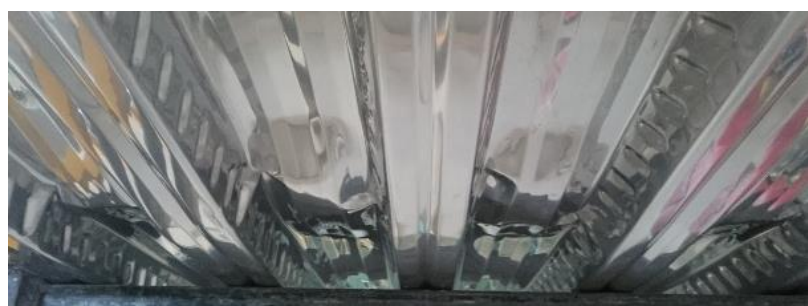

(d)

Fig. 9. Illustrations of longitudinal shear failure a) S1 - D side; b) S1 - E side; c) S3 -cracks at the crack inducer; d) S3 - plastic local failure mode after longitudinal shear failure

\section{PSC DIAGRAM}

Based on the PSC-method, the partial shear connection diagram is determined, in accordance with EN 1994-1-1 annex B.3.6 [1], by varying the degree of shear connection $\eta$ between 0 (no longitudinal shear forces are transmitted by any means) and 1 (a full connection between steel and concrete forming a composite slab acting as one entity). For each degree of shear connection $\eta$, a compressive normal force in the concrete flange $\mathrm{N}_{\mathrm{c}}=\eta \mathrm{N}_{\mathrm{c}, \mathrm{f}}$ is calculated. For a full shear connection, the compressive normal force in the concrete flange $\mathrm{N}_{\mathrm{c}, \mathrm{f}}$ is equal to the plastic resistance of the profiled steel sheeting $\mathrm{N}_{\mathrm{p}}$ and can be determined using Eq. (1). 
$N_{c, f}=N_{p}=A_{p e} f_{y p}$

where $\mathrm{A}_{\mathrm{pe}}$ is the effective cross-sectional area of the profiled steel sheeting (see Table 2),

$\mathrm{f}_{\mathrm{yp}} \quad$ is the yield strength of the profiled steel sheeting (see Table 2).

For each $\mathrm{N}_{\mathrm{c}}$, a corresponding reduced plastic resistance moment of the profiled steel sheeting $\mathrm{M}_{\mathrm{pr}}$, Eq. (2), and a distance between the neutral axis and the extreme fiber of the concrete slab in compression $\mathrm{x}, E q$. (3), can be calculated. The matching lever arm $\mathrm{z}$ between $\mathrm{N}_{\mathrm{c}}$ and $\mathrm{N}_{\mathrm{p}}$ is given by Eq. (4).

$M_{p r}=1.25 M_{p a}\left(1-\frac{N_{c}}{N_{c, f}}\right)<M_{p a}$

where $\mathrm{M}_{\mathrm{pa}}$ is the design value of the plastic resistance moment of the effective cross-section of the profiled steel sheeting (see Table 2).

$x=\frac{N_{c}}{f_{c m} b}$

where $f_{c m}$ is the mean value of the measured cylindrical compressive strength of concrete,

b is the width of the slab (see Table 1).

$z=h_{t}-0.5 x-e_{p}+\left(e_{p}-e\right) \eta$

where $\mathrm{h}_{\mathrm{t}} \quad$ is the overall thickness of the test specimen (see Table 1),

e is the distance from the centroidal axis of profiled steel sheeting to the extreme fibre of the composite slab in tension,

$\mathrm{e}_{\mathrm{p}} \quad$ is the distance from the plastic neutral axis of profiled steel sheeting to the extreme fibre of the composite slab in tension.

Subsequently, $\mathbf{M}_{\mathrm{test}}$, the maximum experimental bending moment, and $\mathrm{M}_{\mathrm{pl}, \mathrm{Rm}}$, the plastic resistance moment of the composite section with full shear connection, can be calculated using Eq. (5) and 
$E q .(6)$, respectively, in which the contribution of the mesh is neglected. The distance between the plastic neutral axis and the extreme fibre of the concrete slab in compression $\mathrm{x}_{\mathrm{pl}}$ (Fig. 1) can be determined using Eq. (7).

$M_{\text {test }}=M_{p r}+N_{c} z$

$M_{p l, R m}=N_{c, f}\left(h-e-0.5 x_{p l}\right)$

$x_{p l}=\frac{N_{c, f}}{f_{c m} b}$

Using Eq. (5) and Eq. (6), the ratio $\mathrm{M}_{\mathrm{tes}} / \mathrm{M}_{\mathrm{pl}, \mathrm{Rm}}$ can be calculated for each degree of shear connection $\eta$, and subsequently be plotted against it (see Fig. 10).

\section{Partial shear connection diagram}

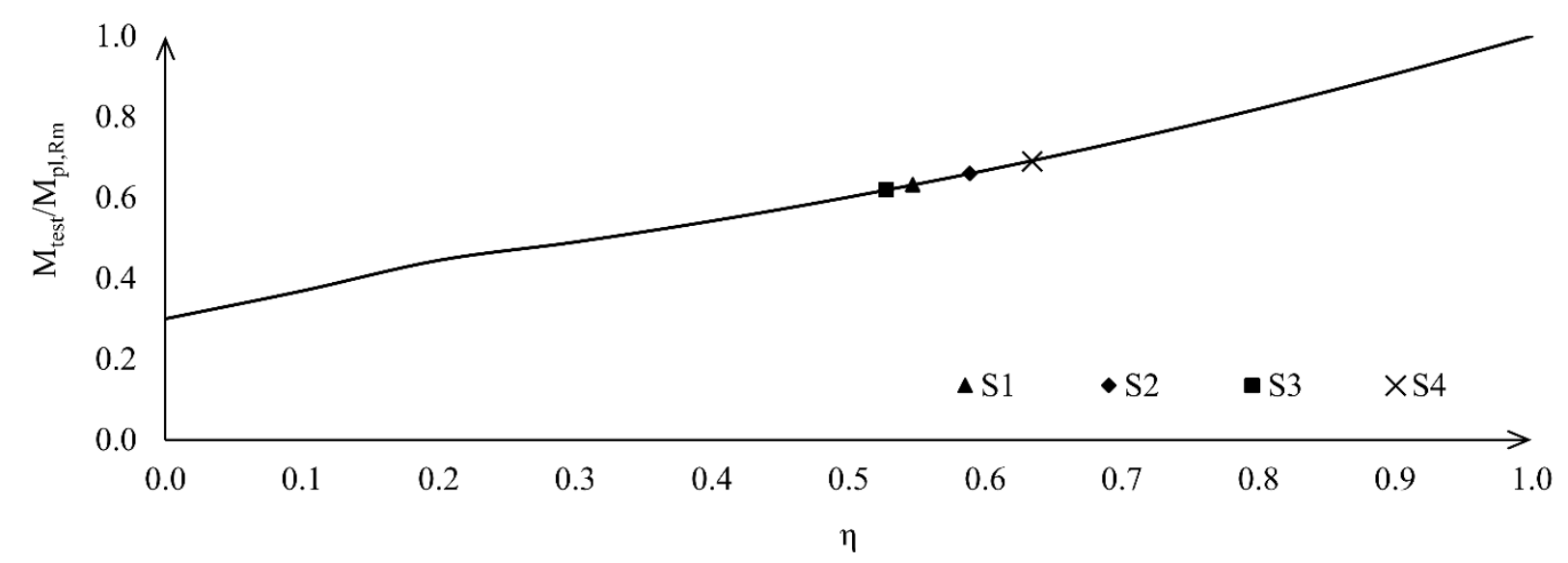

Fig. 10. Partial shear connection diagram for ferritic stainless steel Cofraplus 60

After calculating the ratio $\mathrm{M}_{\mathrm{tes}} / \mathrm{M}_{\mathrm{pl}, \mathrm{Rm}}$ for each test, with $\mathrm{M}_{\mathrm{test}}=\mathrm{F}_{\max } \mathrm{L}_{\mathrm{s}} / 2$ and $\mathrm{M}_{\mathrm{pl}, \mathrm{Rm}}$ determined by Eq. (6), the degree of shear connection $\eta$ can be found on the abscissa from Fig. 10. The corresponding longitudinal shear resistance is calculated using Eq. (8) when excluding the effect of friction at the supports or Eq. (9) when the effect of friction at the supports is considered. The friction coefficient $\mu$ should be taken as 0.5 as recommended in [1].

$$
\tau_{u}=\frac{\eta N_{c, f}}{b\left(L_{s}+L_{o}\right)}
$$


$\tau_{u}=\frac{\eta N_{c, f}-\mu V_{t}}{b\left(L_{s}+L_{o}\right)}$

where $V_{t}$ is the support reaction at the ultimate test load, equal to $F_{\max } / 2$ (see

\section{Table 4),}

$\mathrm{L}_{\mathrm{s}} \quad$ is the length of the shear span (see Table 1),

$\mathrm{L}_{\mathrm{o}} \quad$ is the length of the overhang (100 $\mathrm{mm}$ for all slabs).

The results of the longitudinal shear resistance, with and without friction, are presented in Table 5. The characteristic value $\tau_{\mathrm{u}, \mathrm{Rk}}$ is taken as the 5\%-fractile of the results in accordance with EN 1990 annex D [17] and the design value $\tau_{\mathrm{u}, \mathrm{Rd}}$ is determined by dividing the characteristic value by a partial safety coefficient, in this case $\gamma_{\mathrm{vs}}=1.25$.

Table 5. Longitudinal shear resistance of ferritic stainless steel Cofraplus 60

\begin{tabular}{|c|c|c|c|c|c|}
\hline Slab & $\mathrm{M}_{\text {test }}$ & $\mathrm{M}_{\mathrm{tes}} / \mathrm{M}_{\mathrm{pl}, \mathrm{Rm}}$ & $\eta=\mathrm{N}_{\mathrm{c}} / \mathrm{N}_{\mathrm{c}, \mathrm{f}}$ & $\tau_{\mathrm{u}}(E q .(8))$ & $\tau_{\mathrm{u}}(E q .(9))$ \\
\hline S1 & $12.03 \mathrm{kNm}$ & 0.632 & 0.547 & $0.273 \mathrm{~N} / \mathrm{mm}^{2}$ & $0.251 \mathrm{~N} / \mathrm{mm}^{2}$ \\
\hline S2 & $12.55 \mathrm{kNm}$ & 0.660 & 0.589 & $0.294 \mathrm{~N} / \mathrm{mm}^{2}$ & $0.270 \mathrm{~N} / \mathrm{mm}^{2}$ \\
\hline \multirow[t]{2}{*}{ S3 } & $11.78 \mathrm{kNm}$ & 0.619 & 0.527 & $0.263 \mathrm{~N} / \mathrm{mm}^{2}$ & $0.241 \mathrm{~N} / \mathrm{mm}^{2}$ \\
\hline & & & $\tau_{\mathrm{u}, \mathbf{R d}}=$ & $0.211 \mathrm{~N} / \mathrm{mm}^{2}$ & $0.194 \mathrm{~N} / \mathrm{mm}^{2}$ \\
\hline \multirow[t]{2}{*}{ S4 } & $13.13 \mathrm{kNm}$ & 0.690 & 0.634 & $0.410 \mathrm{~N} / \mathrm{mm}^{2}$ & $0.366 \mathrm{~N} / \mathrm{mm}^{2}$ \\
\hline & & & $\tau_{\mathrm{u}, \mathbf{R d}}=$ & $0.328 \mathrm{~N} / \mathrm{mm}^{2}$ & $0.293 \mathrm{~N} / \mathrm{mm}^{2}$ \\
\hline
\end{tabular}

In [18], composite slabs using identical sheeting and characterized by span lengths of 2500 and $4300 \mathrm{~mm}$ and an overall slab thickness of, respectively, 100 and $180 \mathrm{~mm}$, were tested. The long slabs had a shear span length of $1000 \mathrm{~mm}$ and the short slabs of $550 \mathrm{~mm}$. The corresponding longitudinal shear resistances without considering the effect of friction are equal to $0.099 \mathrm{~N} / \mathrm{mm}^{2}$ and $0.180 \mathrm{~N} / \mathrm{mm}^{2}$, for long and short slabs respectively. The short slabs reported in [18] are very similar to the S1-S3 slabs studied in this research, with the main difference being the span length. The slabs 
in this research are shorter and thus provide a higher value for the longitudinal shear resistance. The ultimate resistance of ferritic stainless steel slabs found herein and in [2] and [18] is similar to that of traditional galvanized steel slabs (with similar yield stress, Young's modulus and steel thickness) and always higher than the nominal resistance of traditional galvanized steel slabs provided in [19].

Besides, in [20], galvanized steel Cofraplus 60 composite slabs were tested. Several differences exist between their specimens and the current ones: the sheet thickness equaled $1.0 \mathrm{~mm}$, the total height was $110 \mathrm{~mm}, \mathrm{C} 20 / 25$ concrete was used and no crack inducers were included. Based on the mean value of the ultimate bending moment of $19.51 \mathrm{kNm}$, a longitudinal shear resistance $\tau_{\mathrm{u}, \mathrm{Rd}}$ of $0.264 \mathrm{~N} / \mathrm{mm}^{2}$ can be attained. Since all above mentioned parameters, except for the concrete strength which has little influence, increase the longitudinal shear resistance, the value for an identical slab would be lower than $0.264 \mathrm{~N} / \mathrm{mm}^{2}$. Thus the ferritic slabs, with a longitudinal shear resistance of $0.211 \mathrm{~N} / \mathrm{mm}^{2}$, can be assumed equivalent to the carbon steel specimens in [20].

\section{CONCLUSION}

Composite slabs using stainless steel sheets offer an improved durability in floors exposed to corrosive environments and fire. Ferritic stainless steel offers mechanical properties comparable to galvanized steel as well as desirable aesthetic appearance and good corrosion resistance. This research considered four stainless steel composite slabs made of EN1.4003 ferritic stainless steel, fabricated via the same production line than for galvanized steel [11].

The slabs were tested according to EN 1994-1-1 annex B.3 [1], except that the slabs were not submitted to a cyclic load of 5000 cycles, but a lower amount, to remove the chemical bond between the steel deck and the concrete. The results confirm that the cyclic loading had no influence on the maximum bending moment, but that the deflection at this maximum load was bigger when no initial cyclic test was previously applied, as stated in previous research works $[6,14,15]$. 
All composite slabs failed in longitudinal shear in a ductile mode. For the three specimens with a span of $1800 \mathrm{~mm}$, an average design value of the longitudinal shear resistance $\tau_{\mathrm{u}, \mathrm{Rd}}$ of $0.211 \mathrm{~N} / \mathrm{mm}^{2}$ was obtained. For the last specimen with a span length of $1300 \mathrm{~mm}, \tau_{\mathrm{u}, \mathrm{Rd}}$ equals $0.328 \mathrm{~N} / \mathrm{mm}^{2}$. The ultimate resistance of ferritic stainless steel slabs calculated herein and in $[2,18]$ is similar to the resistance of slabs made of galvanized steel [20] and always higher than the nominal resistance of galvanized steel slabs [19]. It is therefore concluded that the stainless steel corrugated sheet and the concrete behave as a single structural component and should be considered as such in the design of composite slabs.

\section{CONFLICTS OF INETREST}

None.

\section{ACKNOWLEDGEMENTS}

The Research Foundation Flanders (Belgium) is gratefully acknowledged for its financial support.

\section{REFERENCES}

[1] European Committee for Standardization, Eurocode 4: Design of composite steel and concrete structures - Part 1-1: General rules and rules for buildings. 2004.

[2] M. Ferrer, F. Marimon, I. Arrayago, E. Real, and E. Mirambell, Structural Applications of Ferritic Stainless Steels (SAFSS, RFSR-CT-2010-00026) Deliverable WP3, Task 3.3: Report on "Composite slab tests,” Departament d'Enginyeria de la Construcció. Universitat Politècnica de Catalunya (UPC), 2013.

[3] H. D. Wright and H. R. Evans, "A Review of Composite Slab Design," in Tenth International Specialty Conference on Cold-formed Steel Structures, pp. 27-47, 1990.

[4] S. Chen and X. Shi, "Shear bond mechanism of composite slabs - A universal FE approach," J. Constr. Steel Res., vol. 67, no. 10, pp. 1475-1484, 2011.

[5] P. Mäkeläinen and Y. Sun, "The longitudinal shear behaviour of a new steel sheeting profile for composite floor slabs," J. Constr. Steel Res., vol. 49, no. 2, pp. 117-128, 1999.

[6] N. A. Hedaoo, L. M. Gupta, and G. N. Ronghe, "Design of composite slabs with profiled steel decking: 
a comparison between experimental and analytical studies," Int. J. Adv. Struct. Eng., vol. 3, no. 1, 2012.

[7] European Committee for Standardization, NBN EN 10020. Definition and classification of grades of steel. 2000.

[8] J. Holomek, R. Karásek, M. Bajer, and J. Barnat, "Comparison of Methods of Testing Composite Slabs," Int. J. Mech. Aerospace, Ind. Mechatron. Manuf. Eng., vol. 6, no. 7, pp. 1201-1206, 2012.

[9] B. Peeters and S. De Bruyn, "Longitudinal Shear Resistance of Stainless Steel Composite Slabs: Partial Connection Method,” KU Leuven, Master thesis, 2016.

[10] ArcelorMittal Construction Benelux., “Arval Staalplaatbetonvloer Cofraplus 60gable,” p. 16.

[11] B. Peeters and S. De Bruyn, "Longitudinal Shear Resistance of Stainless Steel Composite Slabs: Partial Connection Method," KU Leuven, 2016.

[12] European Committee for Standardization, "Tests for mechanical and physical properties of aggregates - Part 5: Determination of the water content by drying in a ventilated oven," p. 13, 2008.

[13] European Committee for Standardization, Testing hardened concrete - Part 1: Shape, dimensions and other requirements for specimens and moulds. 2012.

[14] H. Cifuentes and F. Medina, "Experimental study on shear bond behavior of composite slabs according to Eurocode 4,” J. Constr. Steel Res., vol. 82, pp. 99-110, 2013.

[15] H. D. Wright, H. R. Evans, and P. W. Harding, "The use of profiled steel sheeting in floor construction," J. Constr. Steel Res., vol. 7, no. 4, pp. 279-295, 1987.

[16] B. J. Daniels, “Comportement et capacité portante des dalles mixtes - modélisation mathématique et étude expérimentale," p. 33, 1990.

[17] European Committee for Standardization, Eurocode - Basis of structural design. 2015.

[18] M. Ferrer, F. Marimón, I. Arrayago, and E. Mirambell, "Ferritic stainless steel composite slabs: Experimental Study of Longitudinal Shear Transfer," in Proceedings of the seventh European Conference on Steel and Composite Structures (EUROSTEEL), 2014.

[19] CSTB, “Document Technique d'Application 3/15-800," 2015.

[20] J. Holomek, M. Bajer, J. Barnat, and P. Schmid, "Design of composite slabs with prepressed embossments using small-scale tests," Struct. Concr., vol. 16, no. 1, pp. 137-148, Mar. 2015. 